\title{
CrossMark \\ Comparison of the general health and happiness of the elderly living in nursing homes, private homes with and without family-based rehabilitation Services
}

\author{
*Farhad Kahrazei ${ }^{1}$, Azam Akbarizadeh ${ }^{2}$
}

1- Associate Professor, Department of Psychology, Faculty of Education and Psychology, University of Sistan and Baluchestan, Zahedan, Iran (Corresponding Author)

Email: farhad_kahraz@ped.usb.ac.ir

2- Department of Psychology, Zahedan Branch, Islamic Azad University, Zahedan, Iran.

Received: 15 January 2020

Accepted: 24 February 2020

\begin{abstract}
Introduction: Public health and the happiness of the elderly are one of the most important economic, social and health challenges of the twenty-first century due to the phenomenon of increasing their population. This study was conducted with the aim of comparison of the General Health and Happiness of the Elderly Living in Nursing Homes, Private Homes with and without Family-Based Rehabilitation Services.

Methods: The method of this descriptive-analytic study. The statistical population of the study consisted of elderly people living in the family, family members under the family rehabilitation scheme and residents of the elderly in Zabol city in 2017 in 90 people. The sample size was 59 people. However, because of the criteria for entering and homogeneity of society, from each elderly group, 30 were selected by gender ( 15 women and 15 men). The present research tool was the General Health Questionnaire (28 questions form) and the Oxford Happiness Questionnaire. For data analysis and analysis, one-way ANOVA and Tukey's post hoc test were used by SPSS software version 21 .

Results: There was a significant difference between the elderly living at home and the elderly covered by the plan with the difference of mean $(2.47)$ and $(\mathrm{P}=0.01)$. But there was no significant difference between the elderly living in the home and the elderly in the nursing home with respect to the $(\mathrm{P}=$ 0.44). In terms of social functioning, there was a significant difference between the elderly living at home and the elderly covered by the plan with a mean difference (3.33) and $(\mathrm{P}<0.001)$. However, there was no significant difference between the elderly at home and the elderly at home with a significant level $(\mathrm{P}=0.08)$.

Conclusions: Based on the findings of this study, by examining the health of the elderly and their ability to perform their daily activities, health teams and their family members can prevent the progression of their inability to perform life activities and depression.
\end{abstract}

Keywords: Aged, Happiness, Health, Family, Rehabilitation. 


\title{
مقايسه سلامت عمومى و شادكامى سالمنلدان ساكن در سراى سالمنلفان، خانههاى شخصى بهر همنل و فاقد از خلدمات توانبخشى مبتنى بر خانواده
}

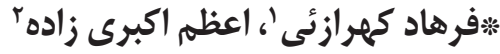 \\ ا - دانشيار، كروه روانشناسى، دانشكدة علوم تربيتى و روان شناسى، دانشخاه سيستان و بلوجستان، زاهدان، ايران (نويسنده مسئول)

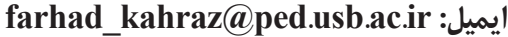 \\ r- كَروه روانشناسى، واحد زاهدان، دانشخاه آَزاد اسلامى، زاهدان، ايران.

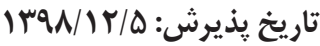

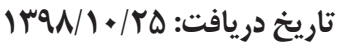

\begin{abstract}
جكيده

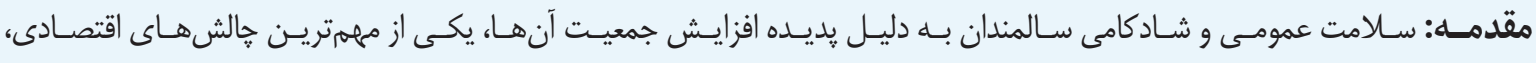

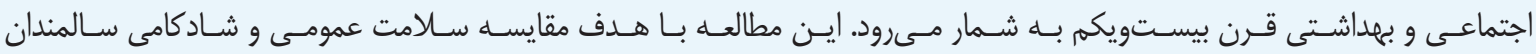

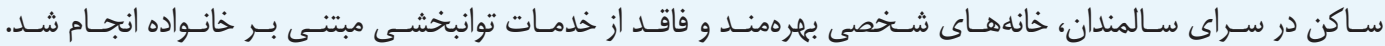

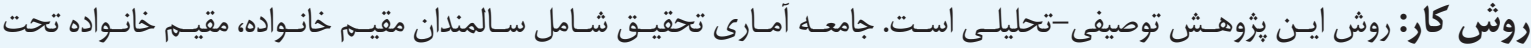

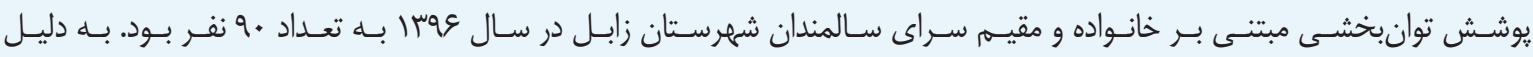

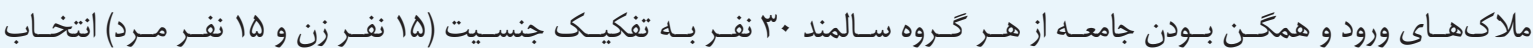

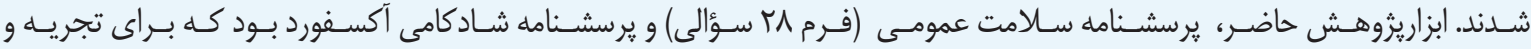

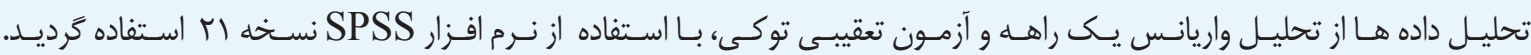

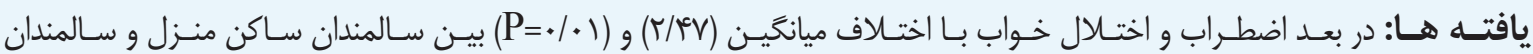

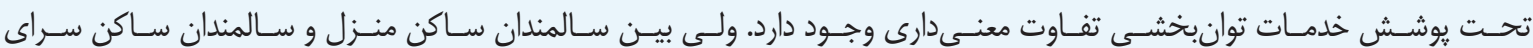

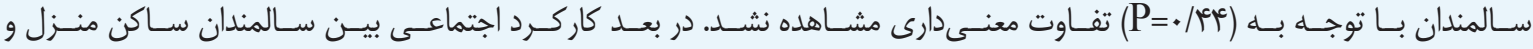

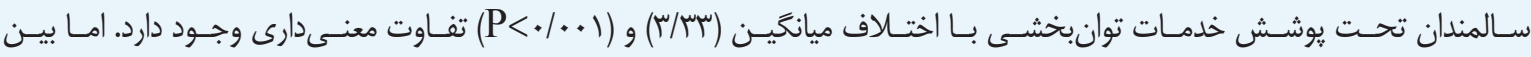

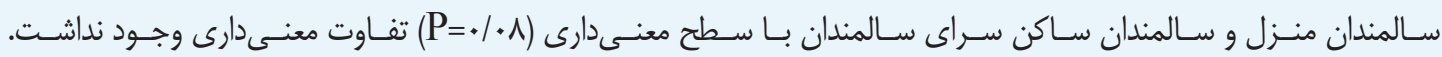

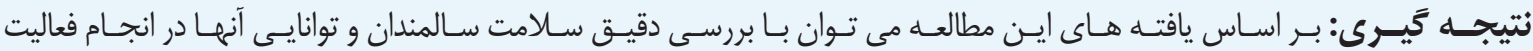

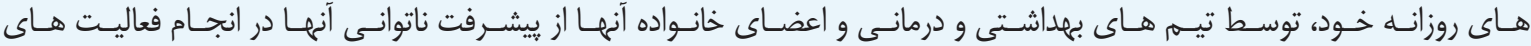

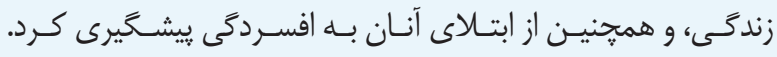

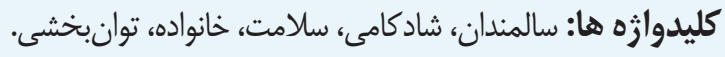

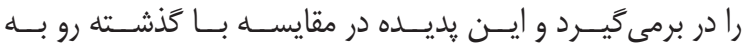

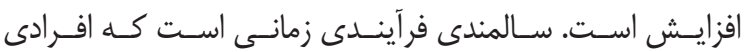

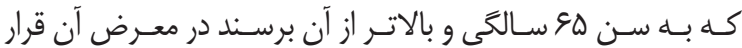

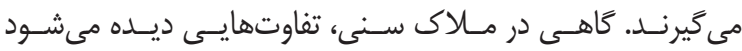

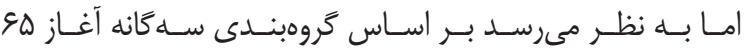

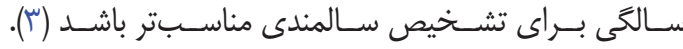

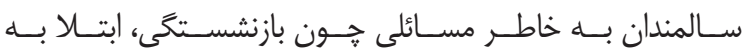

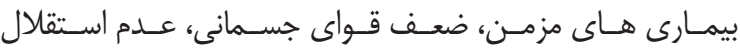

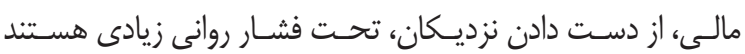

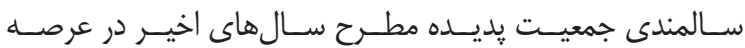

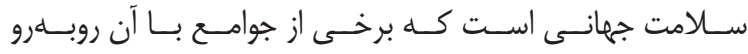

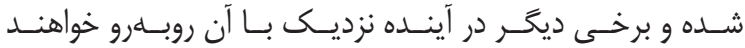

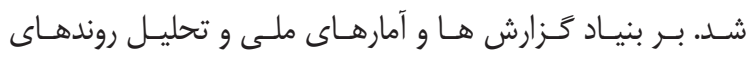

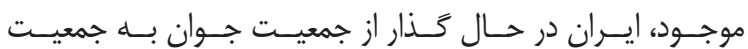

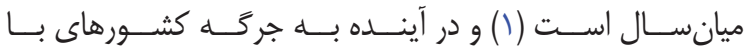

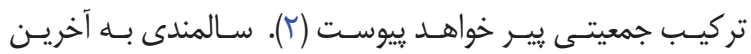

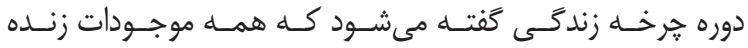




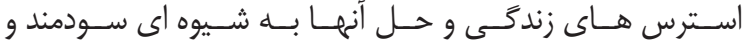

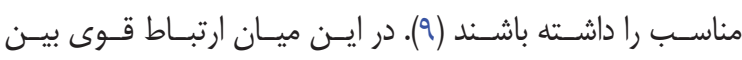

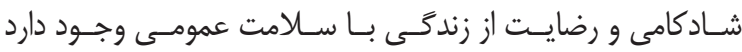

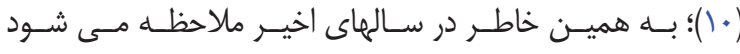

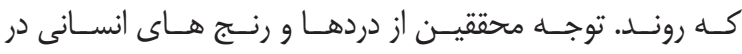

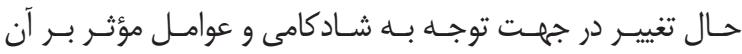

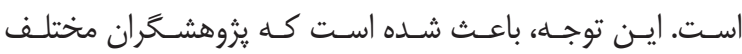

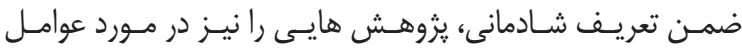

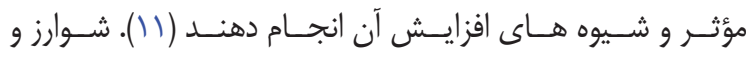

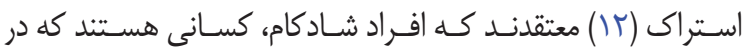
يـردازش اطلاعـات در جهـت خـوش بينى و خوشـالى سـوَّيرى

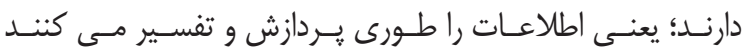

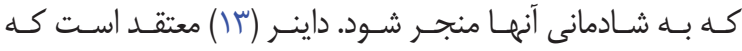

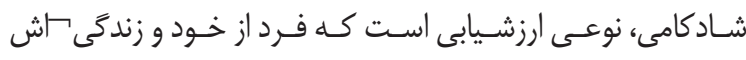

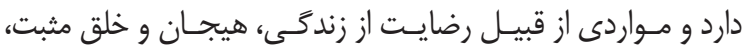

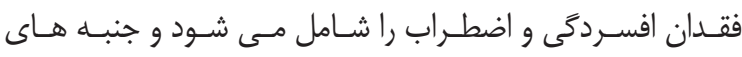

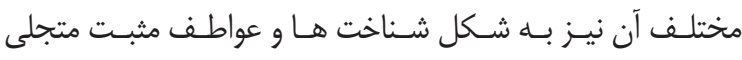

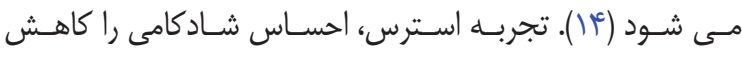

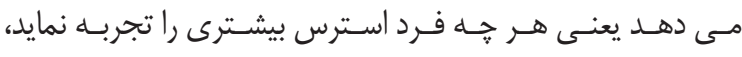

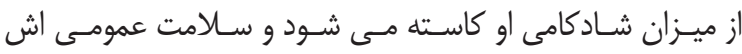

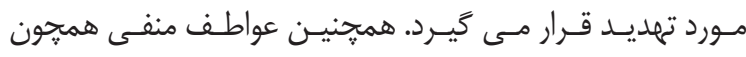

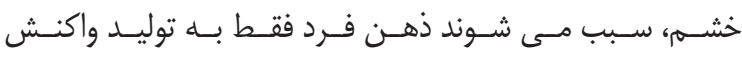

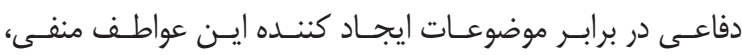

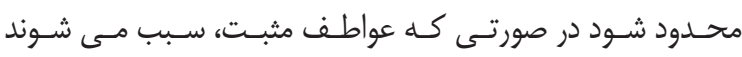

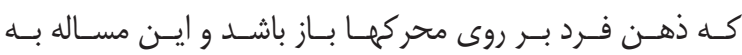

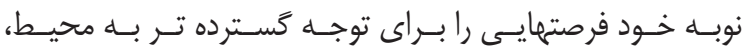

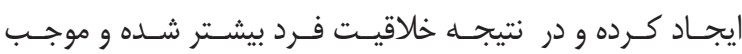

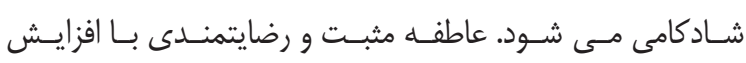

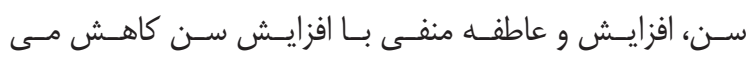

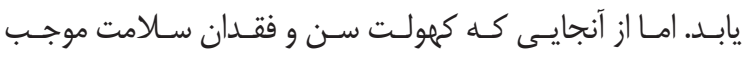

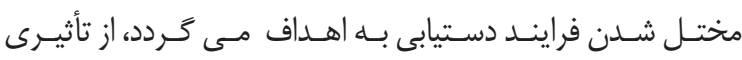

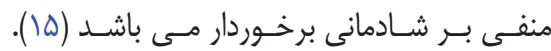

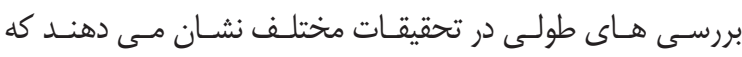

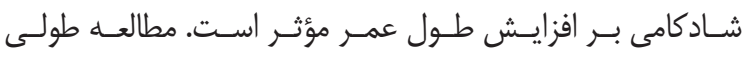

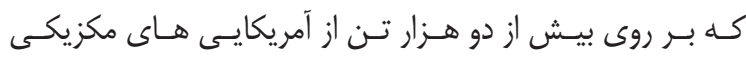

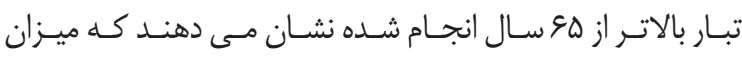

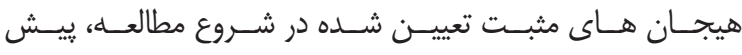

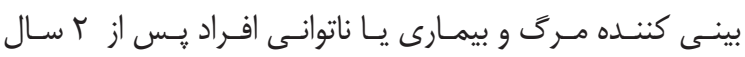

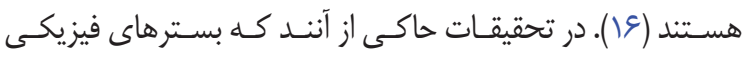

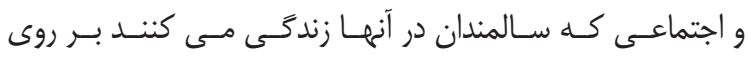

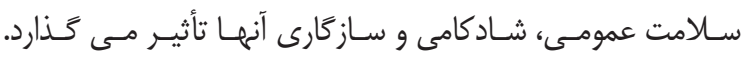

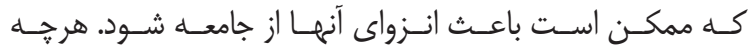

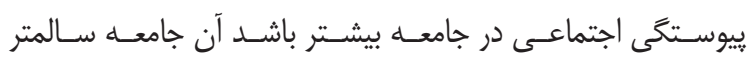

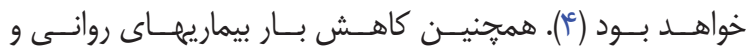

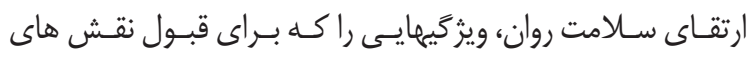

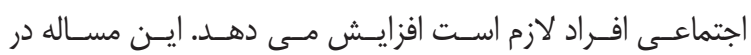

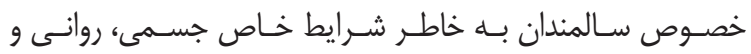

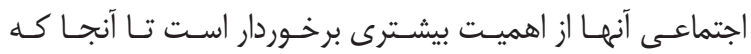

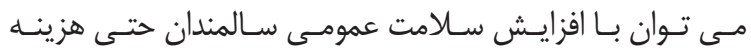

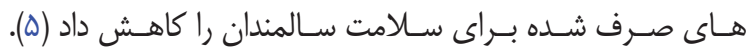

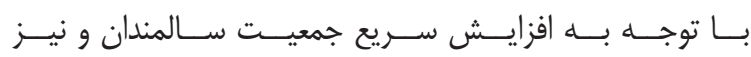

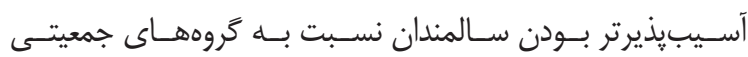

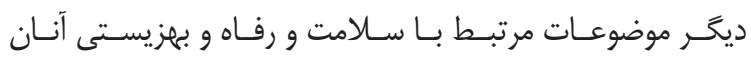

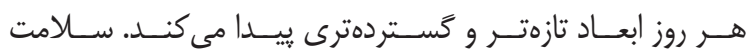

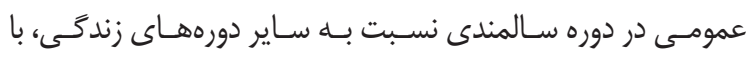

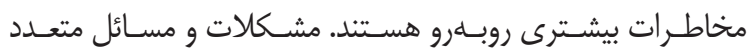

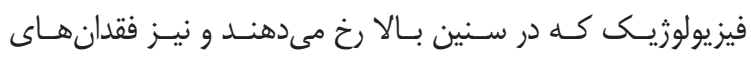

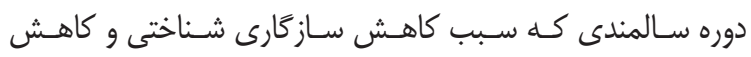

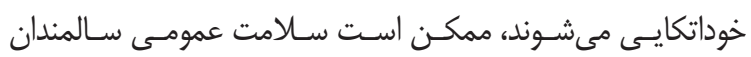

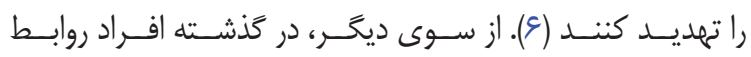

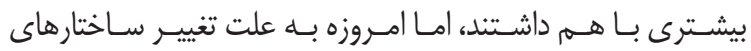

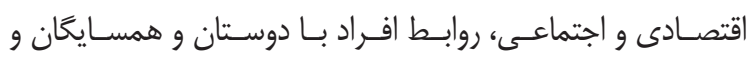

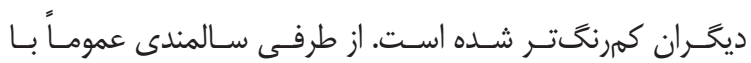

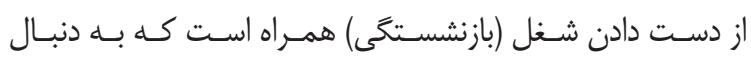

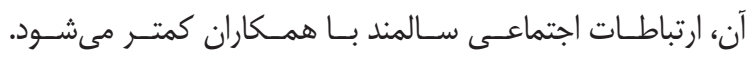

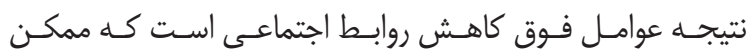

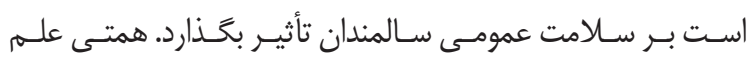

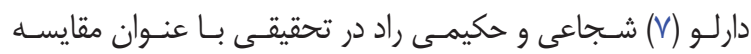

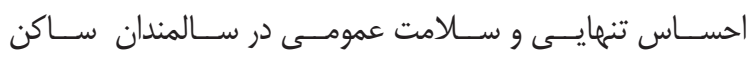

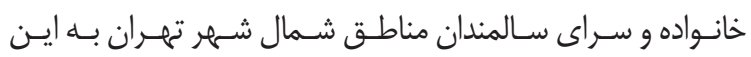

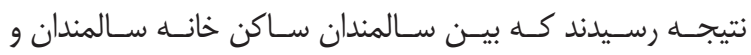

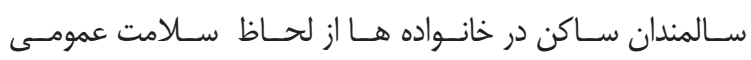
تفـاوت معنسى دارى وجـود دارد.

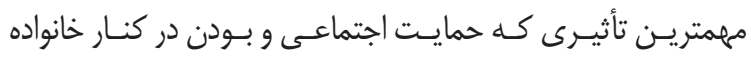

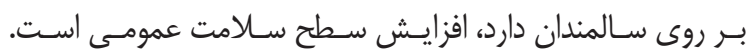

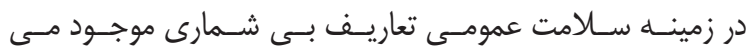

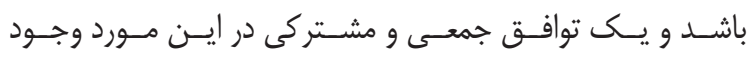

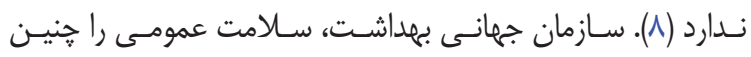

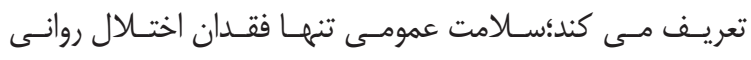

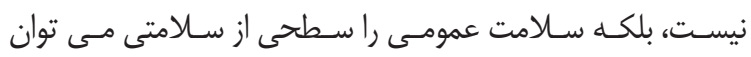

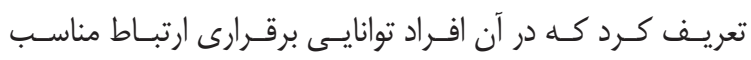

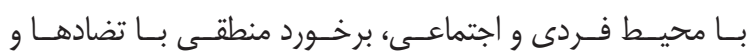




\section{فرهاد كهر ازئى و اعظه اكبرى زاده}

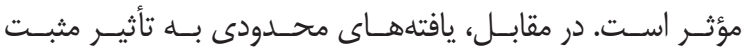

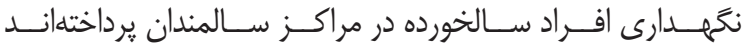

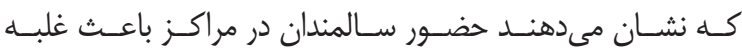

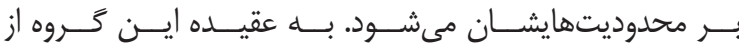

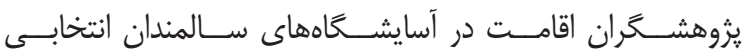

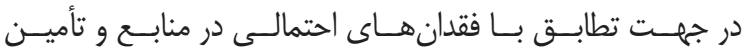

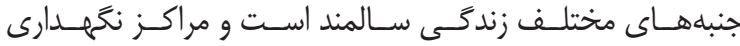

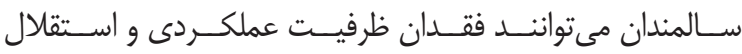

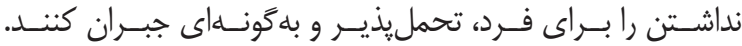

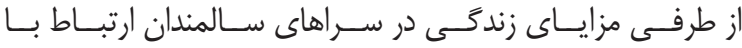

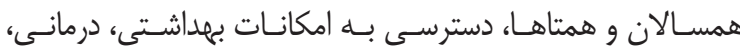

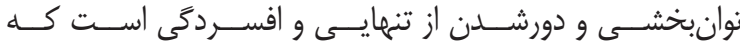

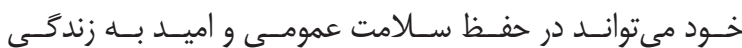

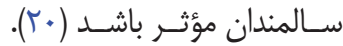

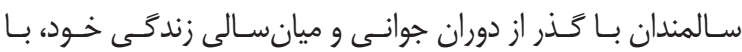
مسـائل و مشـكلات مختلفـى در حــوزه روابـط اجتماعى، سـلامتى ونى

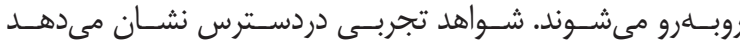

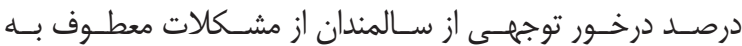
سـلامت جسـمى و روانسى در رنـج هسـتند. بــهـ هميـن دليـل لازم

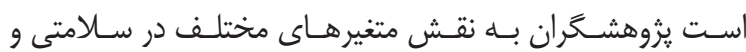

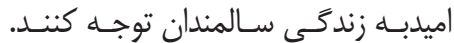

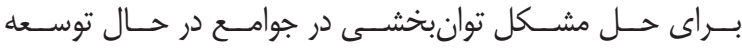

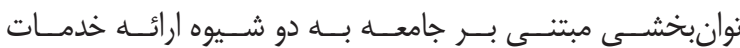

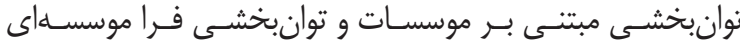

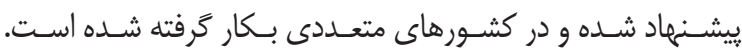

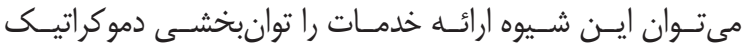

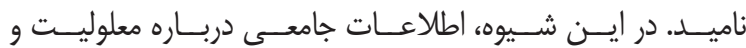
مهمارتهـــاى توانبخشــى در اختيــار افــراد معلـــول، خانـــواده

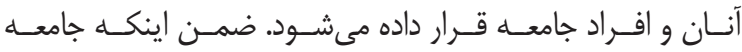

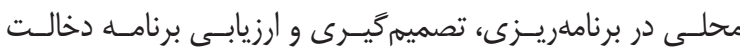

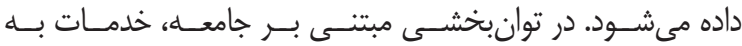

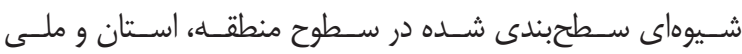

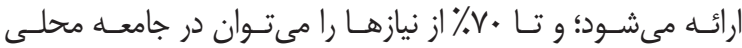

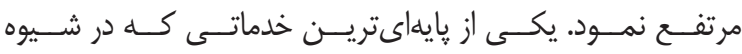

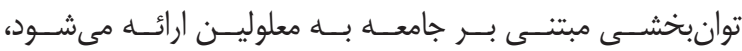

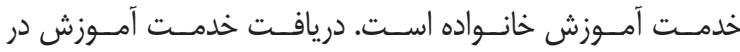

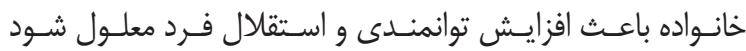

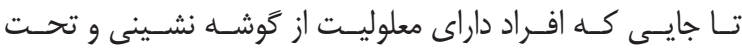

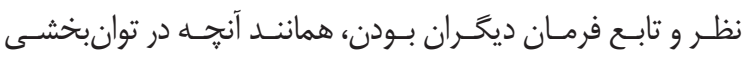

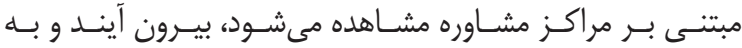

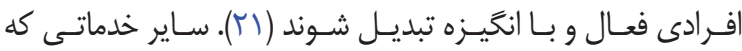

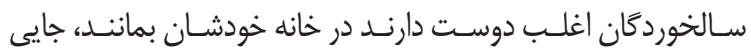

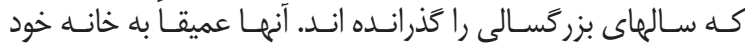

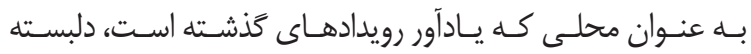
هسـتند و بـراى زندگَى خصوصى و شـبكه دوسـتان و آشـنايان اهميـت زيـادى قائسل انــ، حمايــت اجتماعسى موجـود در محيـط

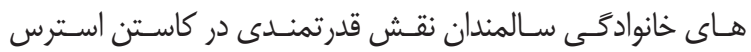

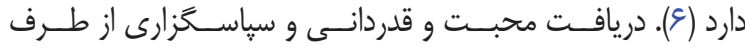

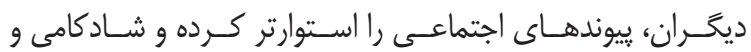

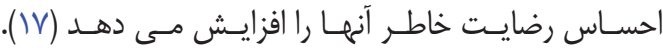

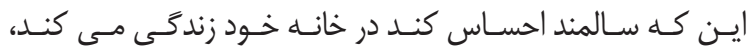

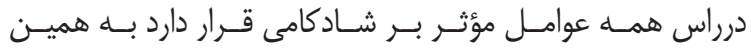

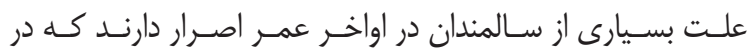

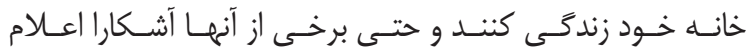

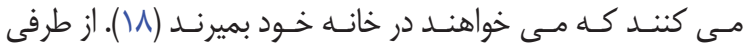

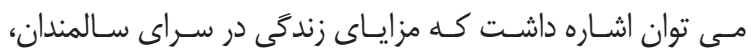

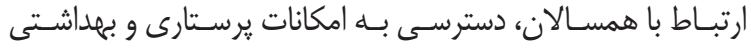

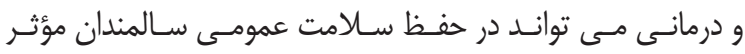
باشـد (19)

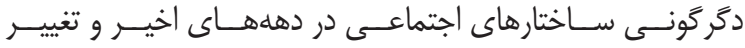

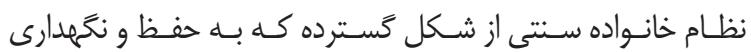

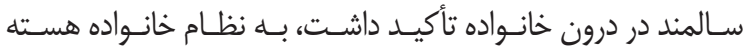

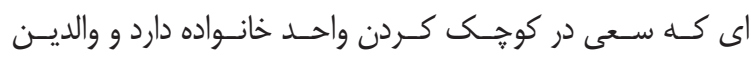

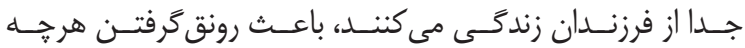

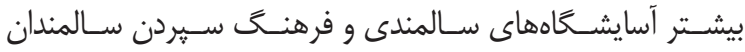

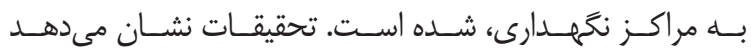

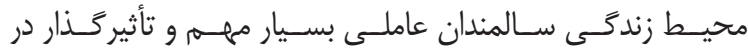

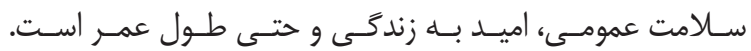

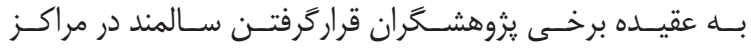

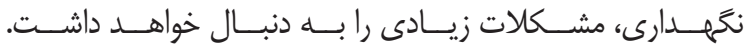
سـالمند وقتـى در خانـهـ سـالمندان قــرار مى گيــرد جــدا از تغييـر

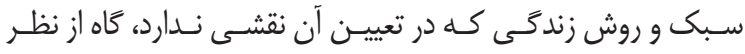

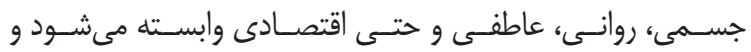

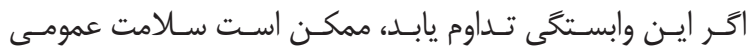

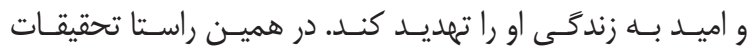

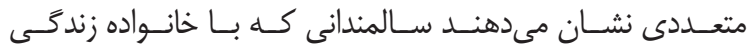

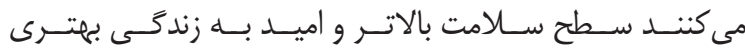

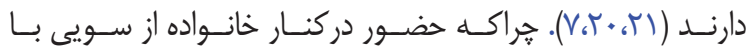

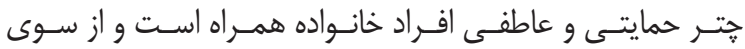

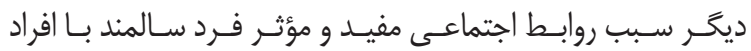

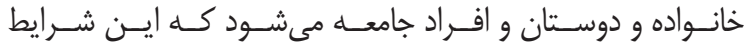

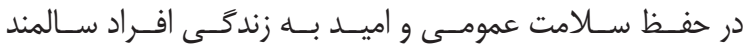




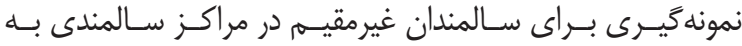

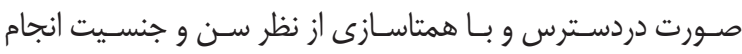

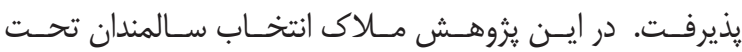

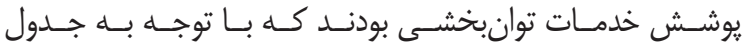

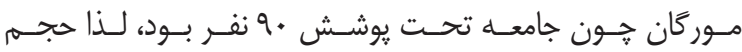

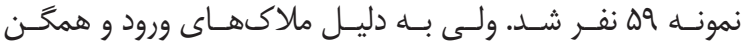

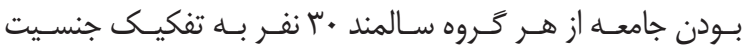

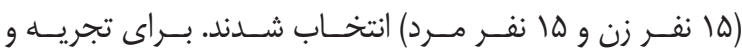

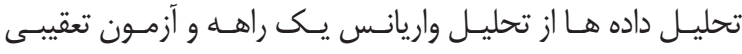

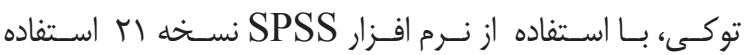

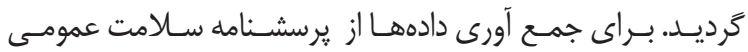

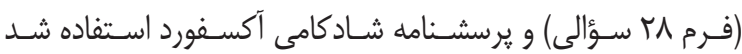

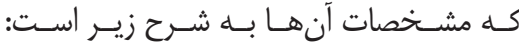

$$
\begin{aligned}
& \text { يرسشنامه سلامت عمومى (فرم ب سؤالى) }
\end{aligned}
$$

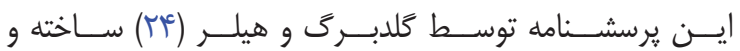

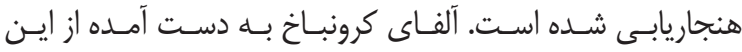

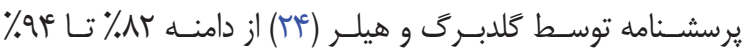

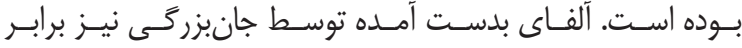

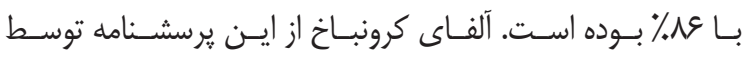

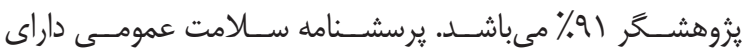

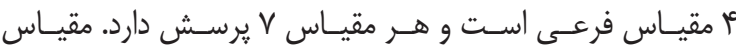

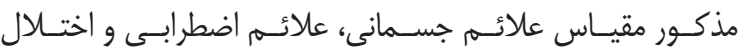

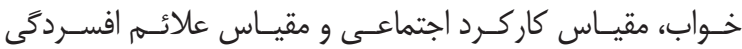

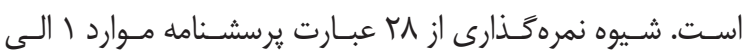

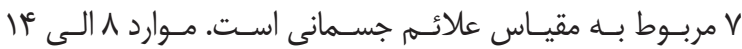

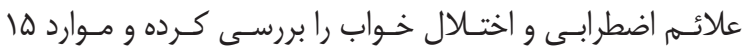

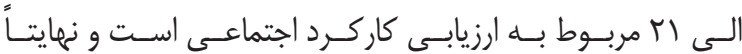

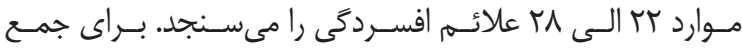

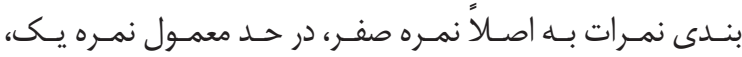

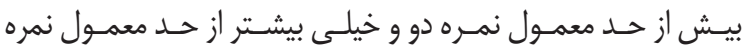

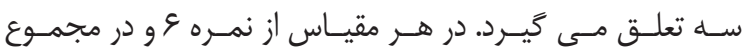

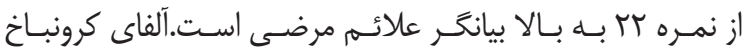

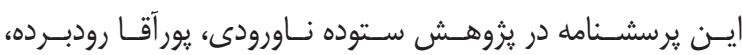

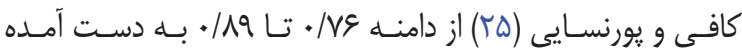

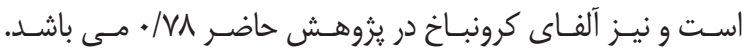

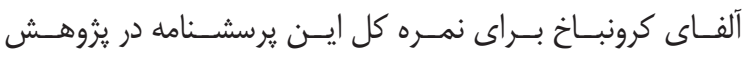

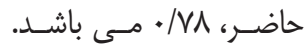
بر برشنامه شادكامى آكسفورد

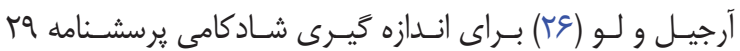

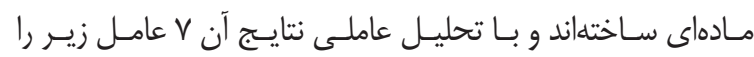

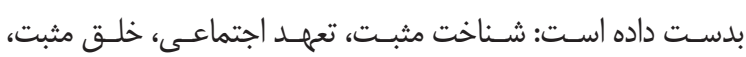

در توانبخشـى مبتنسى بــر جامعـهـ عـلاوه بــر آمـوزش خانسواده

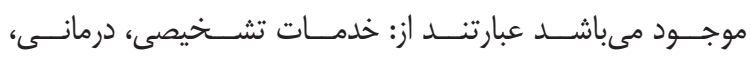

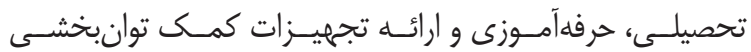

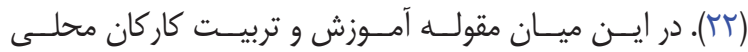

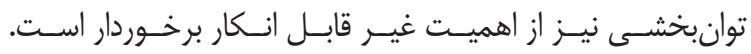

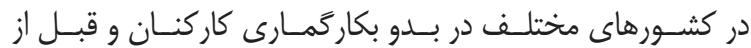

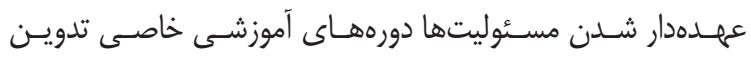

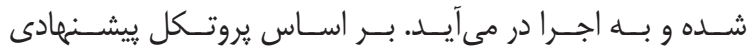

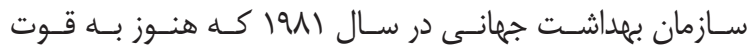

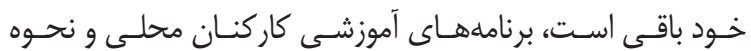

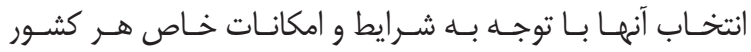

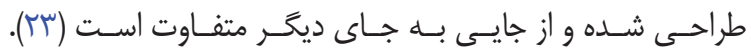

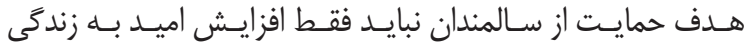

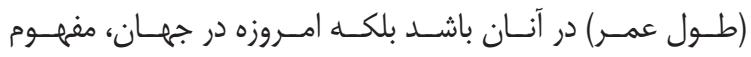

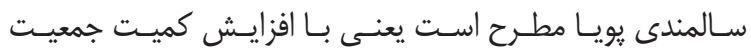

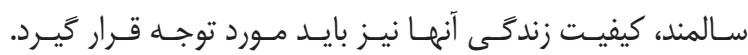

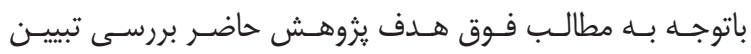

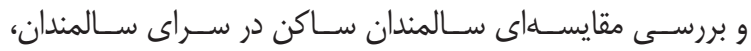

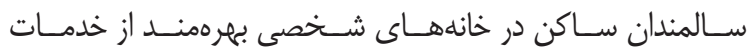

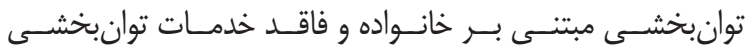

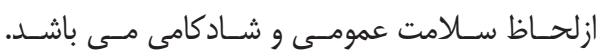

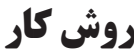

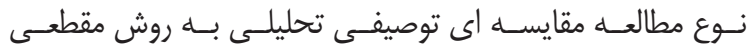

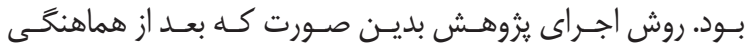

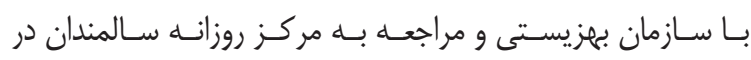

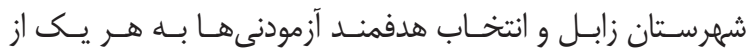

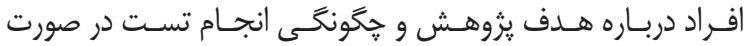

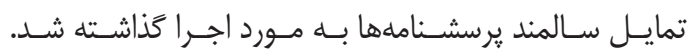
جامعـهـ آمـارى تحقيـق شـامل سـالمندان مقيـمم خانـواده، مقيسم

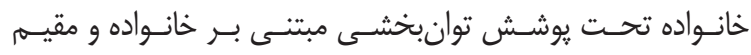

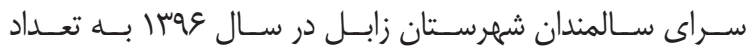

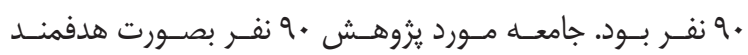

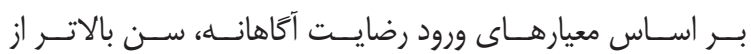

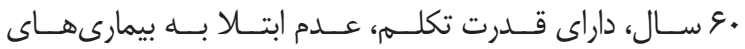

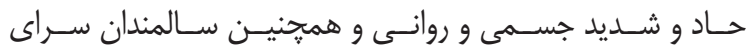

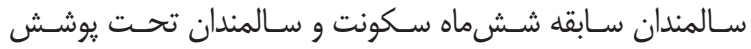

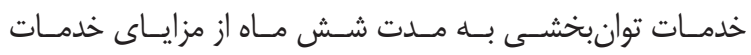

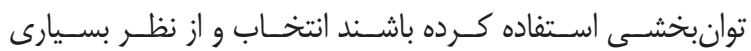

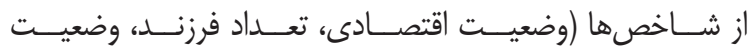

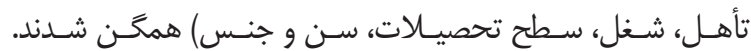


مشـاركت در تحقيـق موجـب هيجِكَونـهـ بــار مالـى بـراى شـركت

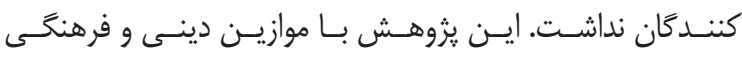

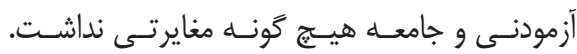

يافته ها

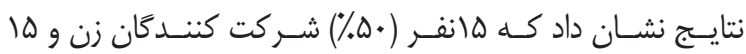

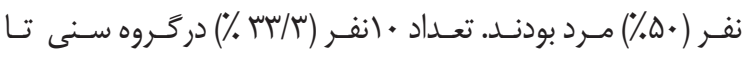

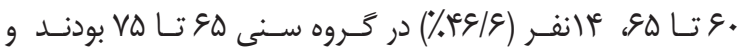

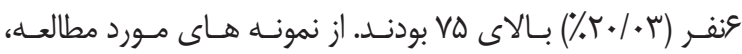

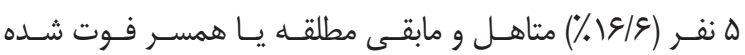

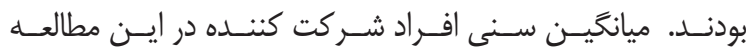

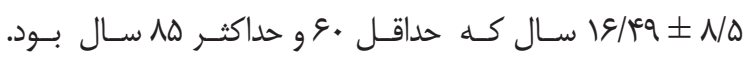

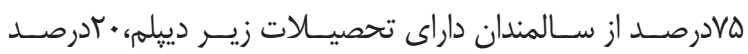

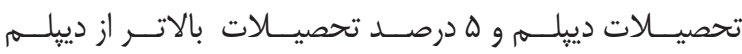

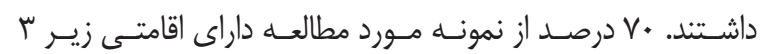

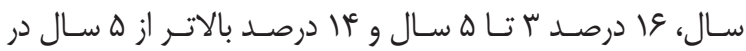
خانــه سـالمندان اقامـت داشـتند.
احسـاس كنتـرل زندگَى، سـلامت جسـمى، رضايـت از خويشـتن

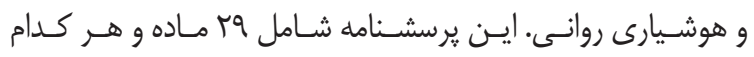

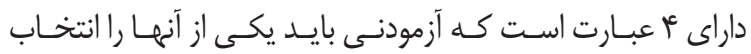

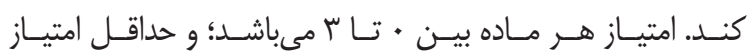

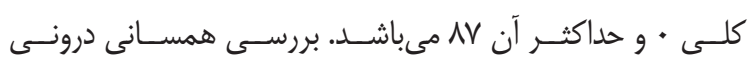

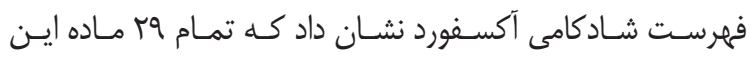

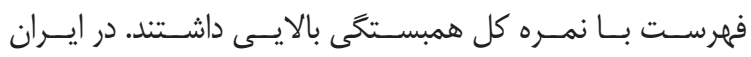

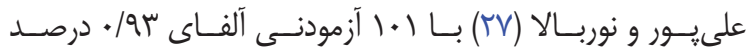

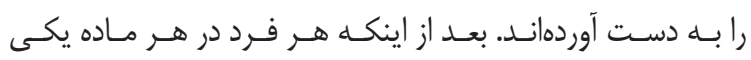

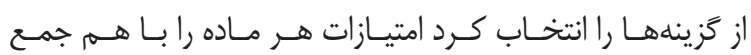

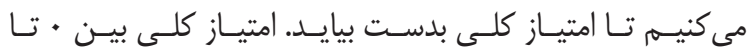

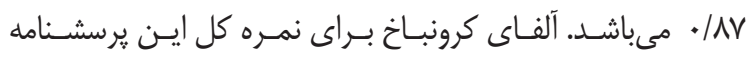

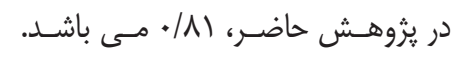

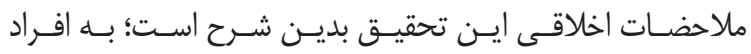

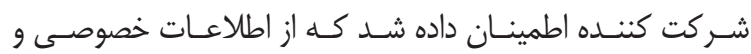

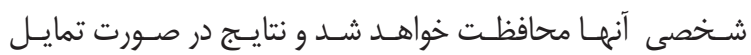

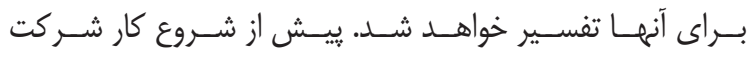

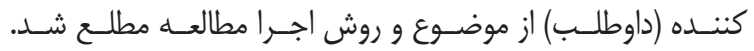

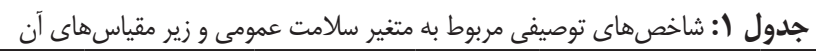

\begin{tabular}{|c|c|c|c|c|c|c|}
\hline مقدار ييشينه & مقدار كمينه & انحراف معيار & ميانكَين & تعداد & كروه & متغير \\
\hline IV & 1 & $\Delta / T \Delta$ & $\Lambda / \& V$ & r. & منزل & \\
\hline I & r & $r / 99$ & N/DT & $\mu$. & مراقبين خانكى & \\
\hline ז & r & $r / 91$ & $9 / 4$ & r. & سراى سالمندان & عالتم جسمالى \\
\hline 10 & f & M/gr & $1 . / \cdot \cdot$ & r. & منزل & \\
\hline r & - & $r / v \mu$ & V/DT & r. & مراقبين خانكى & \\
\hline ז & 1 & $r / \kappa$. & N/9V & r. & سراى سالمندان & علانم اصطراب و احسال حواب \\
\hline IV & r & $\Gamma / \Gamma \Delta$ & $11 / 1 \pi$ & r. & منزل & \\
\hline ir & r & $r / 11$ & $\mathrm{~V} / \mathrm{A}$. & $\mu$. & مراقبين خانكى & مقاس كا.ر5 د احتماء \\
\hline 14 & r & $r / \uparrow \wedge$ & $9 / 9 V$ & r. & سراى سالمندان & 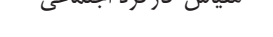 \\
\hline 115 & - & r/19 & r/AV & r. & منزل & علائم افس دخ \\
\hline IV & - & $r / r q$ & $\mu / \mu$. & r. & مراقبين خانكى & 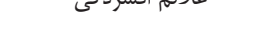 \\
\hline ri & 1 & $r / \varphi^{c}$ & $\Delta / \mu^{*}$ & $\mu$. & سراى سالمندان & \\
\hline$\Delta \wedge$ & 18 & $I T / V \Lambda$ & $M C / g V$ & r. & منزل & \\
\hline$\Delta r$ & 11 & 1.109 & $\mathrm{TV} / \mathrm{IV}$ & r. & مراقبين خانكى & ساذهـ عمومى \\
\hline et & 9 & $N M$ & 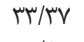 & r. & سراى سالمندان & \\
\hline r & - & N/99 & $1 \pi / 9$. & r. & منزل & رضايت از زندگً \\
\hline rq & · & $V / \backslash \Delta$ & $1 \mathrm{r} / \mathrm{W}$ & $r$. & مراقبين خانكى & \\
\hline r. & r & $V / r q$ & $10 / 1$. & r. & سراى سالمندان & \\
\hline 19 & · & $\Delta / v \wedge$ & $1 . / 9$. & r. & منزل & خلق مشت \\
\hline$r$. & 1 & $r / 9)^{c}$ & $1 . / W$ & r. & مراقبين خانكَى & 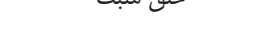 \\
\hline re & r & $\Delta / \cdot 9$ & $11 / \Delta T$ & r. & سراى سالمندان & \\
\hline 19 & - & $\Gamma / \Lambda \Delta$ & s/A. & r. & منزل & سلامتت \\
\hline 10 & - & $4 / .9$ & $V / \Delta$. & r. & مراقبين خانكى & 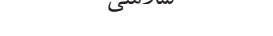 \\
\hline 18 & 1 & $r / r q$ & $V / N$ & r. & سراى سالمندان & \\
\hline ir & - & $r \cdot / 4 q$ & r/A & r. & منزل & كا, آمدى \\
\hline 1. & - & T/QT & r/qu & r. & مراقبين خانكىى & مارן \\
\hline 11 & - & עז/א & $r / v$. & r. & سراى سالمندان & \\
\hline$\Delta$ & - & I/A & T/T & r. & منزل & \\
\hline$\Delta$ & - & I/rT & $r / v \cdot$ & r. & مراقبين خانكى & عرك سمس \\
\hline 9 & - & $1 / \mathrm{VV}$ & $r / \Delta V$ & r. & سراى سالمندان & \\
\hline$\lambda i^{4}$ & r & 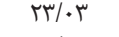 & r $1 / \mu^{\prime}$ & r. & منزل & شادكام \\
\hline $\mathrm{v \wedge}$ & r & W/GT & एव/दV & r. & مراقبين خانكى & 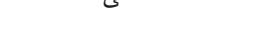 \\
\hline$\Lambda \mathrm{V}$ & • & $r \cdot / 4$. & Fi/gr & r. & سراى سالمندان & \\
\hline
\end{tabular}




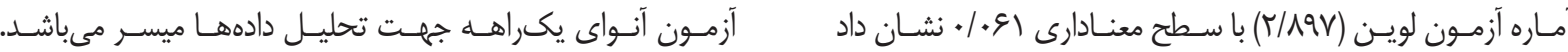

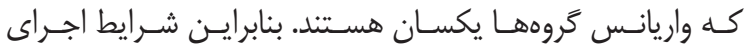

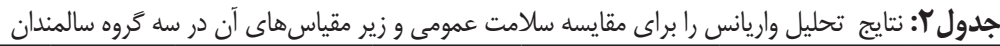

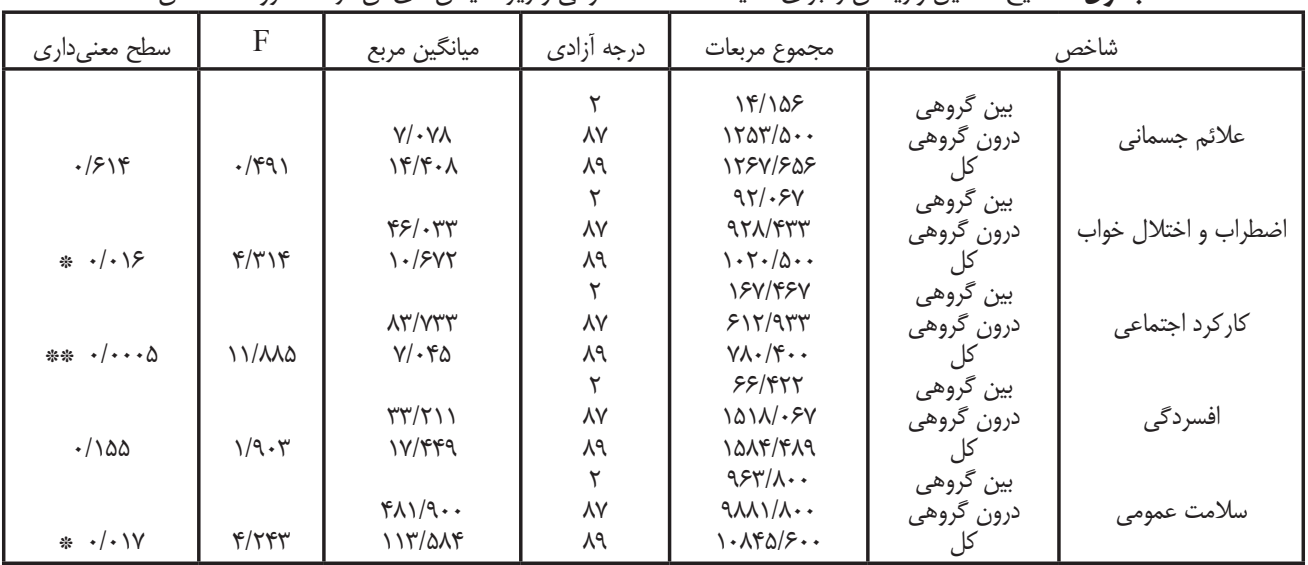

$*<\%, g_{*} * * \% 1$

جدول"ا: نتايج آزمون تعقيبى توكى مقايسهاى زوجى كروههاى سالمندان در مقياس سلامت عمومى و ابعاد آن

\begin{tabular}{|c|c|c|c|c|}
\hline 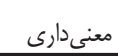 & اختلاف ميانكين بين دو كروه (I-J) & (J) كروه & كروه & مقياس \\
\hline $.1 .1 \% *$ & T/e & مراقبين خانكَي & & اضطراب و اختلال خواب \\
\hline $.1 \% *$ & $-T / \mathscr{F V}$ & ما منزل & سراي سالمنا & \\
\hline.$|r|$ & $-1 / 44$ & سراى سالمندان & & \\
\hline 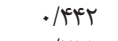 & $-1 / . \mu$ & مان منزل & & \\
\hline $\begin{array}{l}\cdot / r \| 11 \\
. \cdots \Delta * * 4\end{array}$ & 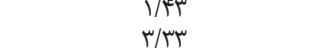 & 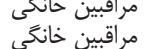 & & \\
\hline$\cdot / \cdot M$ & 1/Fr & سراى سالمندان & & كاركرد اجتماعى \\
\hline $1 \cdots \Delta$ * * & - & 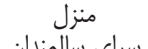 & سراى سالمندان & \\
\hline $\begin{array}{l}1 . \mathrm{M} * \\
.1 . \mathrm{M}\end{array}$ & $\begin{array}{l}-1 / / V \\
-1 / \% V\end{array}$ & سراى سالمندان & & \\
\hline 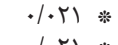 & $1 / A V$ & مراقبين خانِكَى & & \\
\hline $\begin{array}{l}\cdot / r T * * \\
. M F^{*}\end{array}$ & $\begin{array}{l}V / \Delta . \\
1 / \Gamma .\end{array}$ & 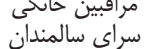 & & \\
\hline.$/ r r *$ & $-V / \Delta$. & 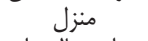 & 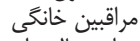 & \\
\hline .1 .91 & $-9 / \pi$. & سراى سالمندان & سراى سالمندان & سلامت عمومى \\
\hline $\begin{array}{l}. / M Y \\
.1 .91\end{array}$ & $\begin{array}{l}-1 / \pi . \\
9 / \pi .\end{array}$ & مراقيبين خانكى & & \\
\hline
\end{tabular}

$*<\% \Delta, * * \%<\%$

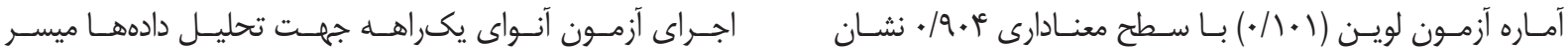

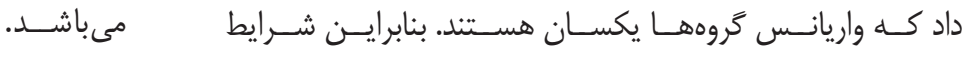
جدول ff: نتايج تحليل واريانس را براى مقايسه شادكامى و زير مقياس هائ آن در سه كروه سالمندان

\begin{tabular}{|c|c|c|c|c|c|c|}
\hline سطح معنى دارى & $\mathrm{F}$ & ميانگين مربع & درجه آزادى & مجموع مربعات & \multicolumn{2}{|c|}{ شاخص } \\
\hline.$/ 114$ & T/TET & $\begin{array}{l}\text { g/VII } \\
\text { r/991 }\end{array}$ & $\begin{array}{l}r \\
1 V \\
19\end{array}$ & $\begin{array}{l}\text { Ir/Ert } \\
r g . / r q V \\
r V / Y \Lambda q\end{array}$ & درون گرَوهى & رضايت از زندگى \\
\hline - /DQ &.$/ D I V$ & $\begin{array}{l}\text { T/VEF } \\
\text { Q/TIY }\end{array}$ & $\begin{array}{l}r \\
1 V \\
19\end{array}$ & $\begin{array}{l}0 / \& \wedge q \\
\mid F T / \backslash \& V \\
\leftarrow \& V / \& \Delta \&\end{array}$ & درون گروهى كروهى & خلق مثبت \\
\hline$* * 1+\cdots \Delta$ & $11 / M \Delta$ & $\begin{array}{l}\Lambda r / V r r \\
V / \cdot \kappa^{\prime} \Delta\end{array}$ & $\begin{array}{l}r \\
1 V \\
19\end{array}$ & $\begin{array}{l}\text { IEV/KGV } \\
\text { GIY/QTY } \\
V \Lambda \cdot / K+.\end{array}$ & درون گرَورهى & سلامتى \\
\hline$\cdot / \Delta V^{c}$ & $\cdot / \Delta \Delta 9$ & $\begin{array}{l}m / r / m \\
r / q \mid r\end{array}$ & $\begin{array}{l}r \\
1 V \\
19\end{array}$ & $\begin{array}{l}90 / \& \wedge q \\
9 V \times / \wedge . . \\
V 9 q / / 19 q\end{array}$ & درون گرَّوهى & كار آمدى \\
\hline$* * \cdot+r$ & S/NEV & $\begin{array}{l}\Delta 1 / V^{e} Y^{C} \\
V / \Delta \Delta V\end{array}$ & $\begin{array}{l}r \\
1 V \\
19\end{array}$ & $\begin{array}{l}1 . r / 4 \wedge 9 \\
90 V / 0 . . \\
V 9 . / 9199\end{array}$ & درون گرَروهى & عزت نفس \\
\hline$* * 1 \cdots \Delta$ & $|r / v|$. & $\begin{array}{l}F|\Delta / V| 1 \\
r \cdot|\Delta|^{4} \mid\end{array}$ & $\begin{array}{l}r \\
19 \\
19\end{array}$ & 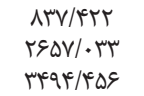 & درون گرَوهى & \\
\hline
\end{tabular}


جدوله: تايج آزمون تعقيبى توكى مقايسههاى زوجى كروههاى سالمندان در مقياس شادكامى و ابعاد آن

\begin{tabular}{|c|c|c|c|c|}
\hline 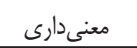 & اختلاف ميانخين بين دو گروه (I-J) & (J) & كروه & شاخص \\
\hline 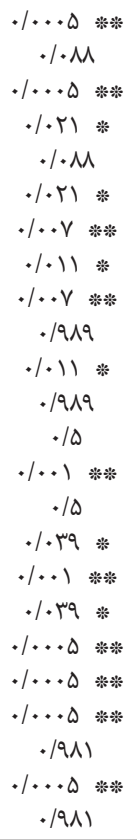 & 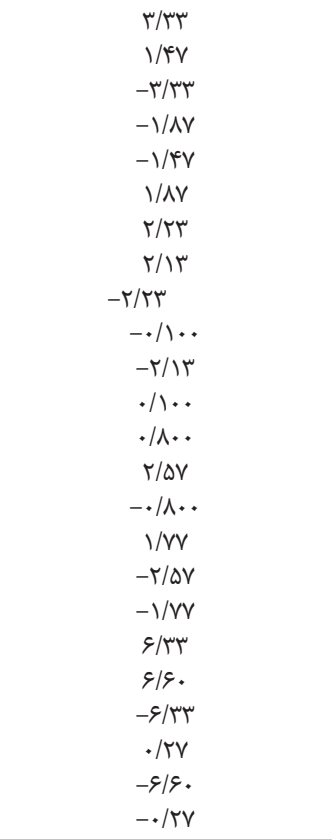 & 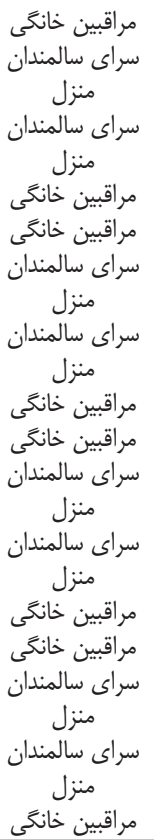 & 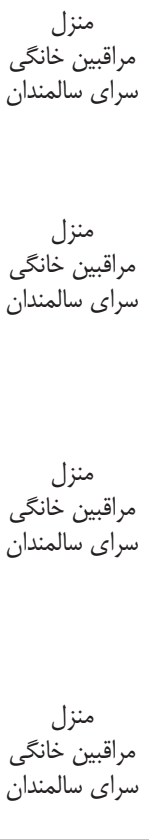 & 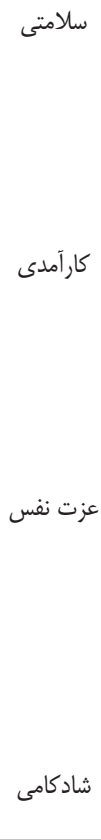 \\
\hline
\end{tabular}

شـرايط بهداشـتى، تعداد بيشـترى از جمعيت به سـن سـالخوردخى

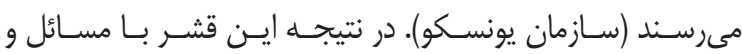

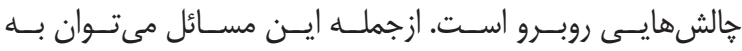

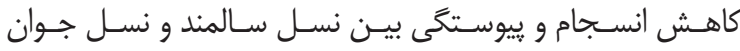

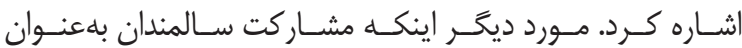

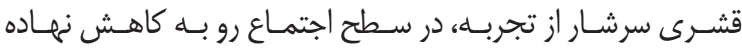

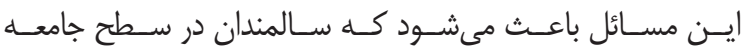

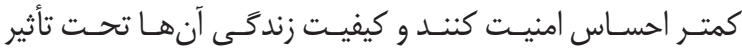

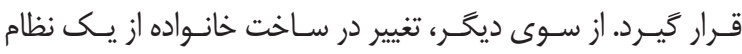

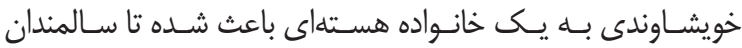

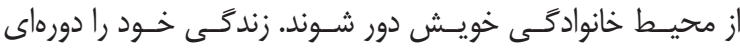

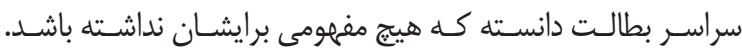

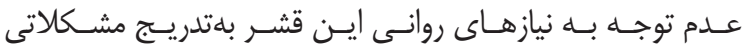

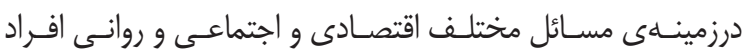

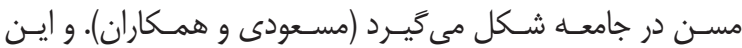

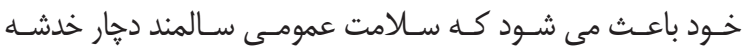

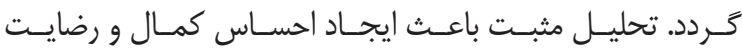

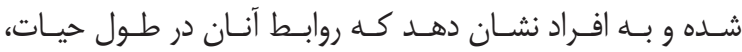

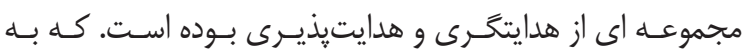

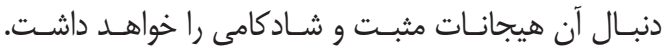

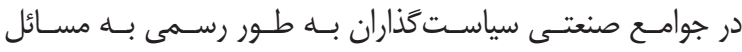

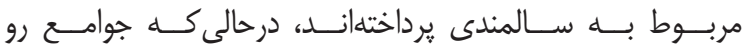

نتايـج نشـان داد كـهـ شـادكامى سـالمندان سـاكن منـزل كمتـر

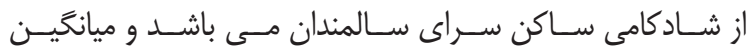

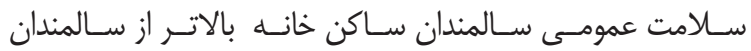

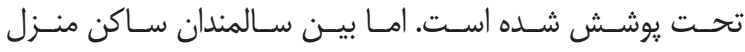

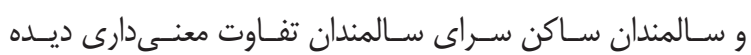

\section{نشـــ.}

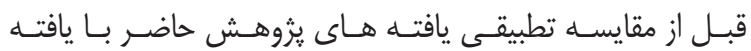

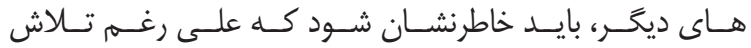

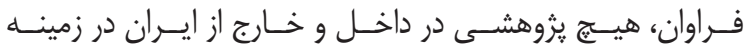

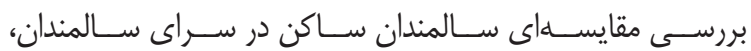

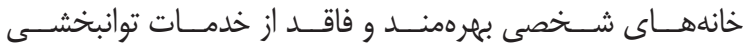

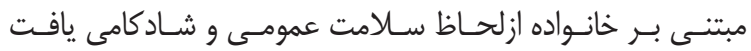

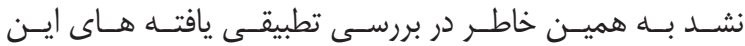

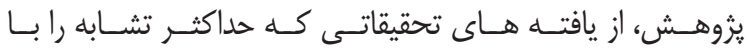

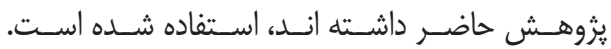

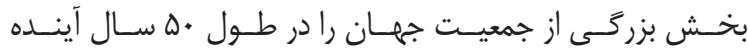

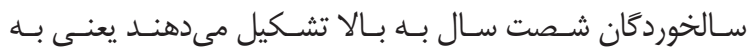
ازاء هــر ه نفــر يـك نفــر سـالمند وجــود دارد. در سـالهاى اخيـر

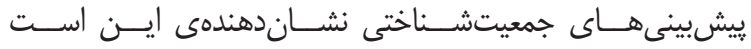

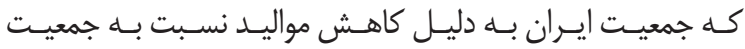

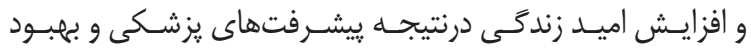




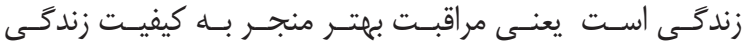

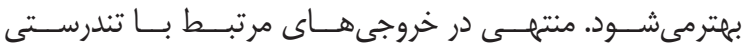

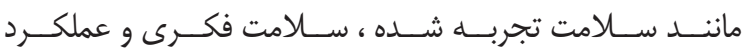

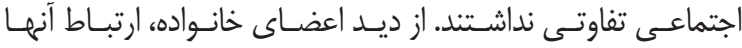

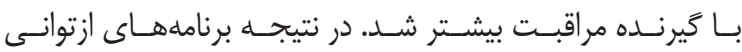

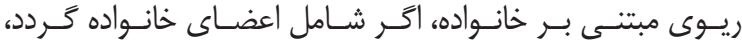

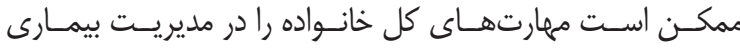

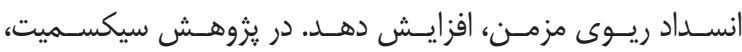

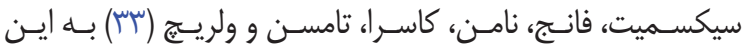

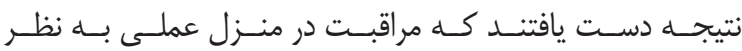

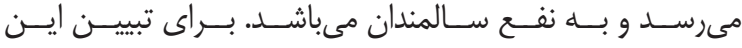

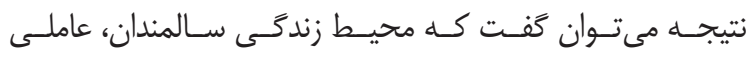

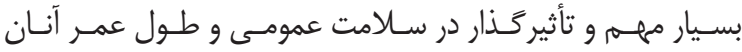

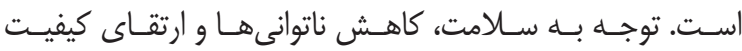

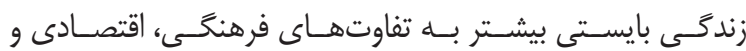

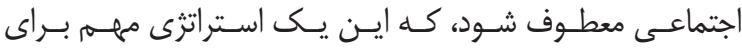

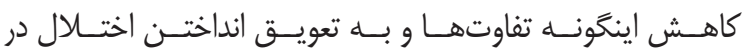

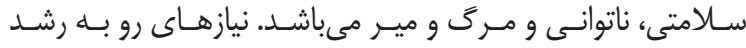

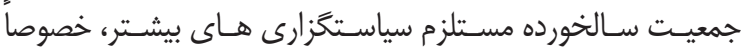

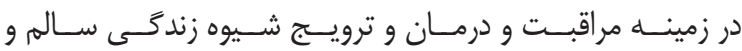

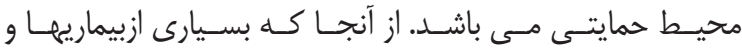

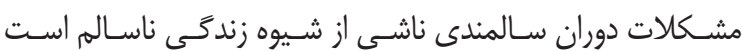

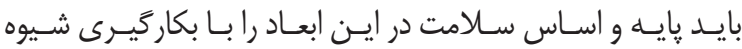

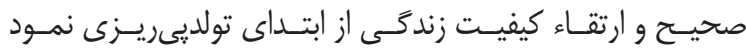

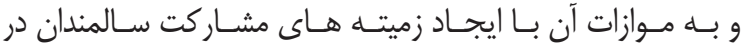

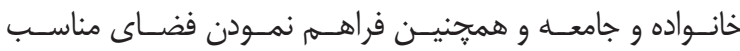

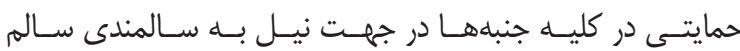

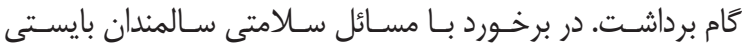

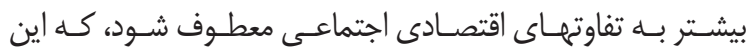

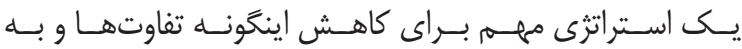
تعويـق انداختـن اختـلال در ســامتى، ناتوانسى و مـركى و ميــر

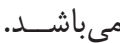

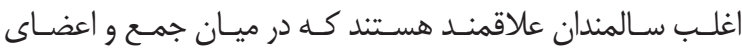

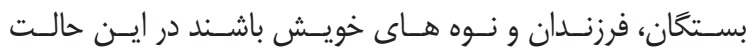

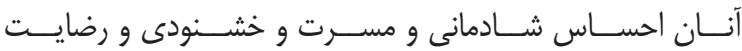

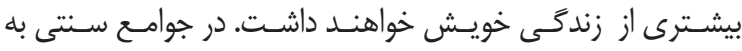

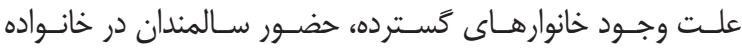
امـكان هذيـر مسى خـردد؛ در مناطـق روسـتايى و عشـايرى ايـران،

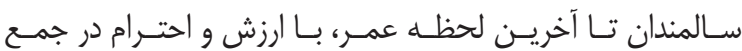

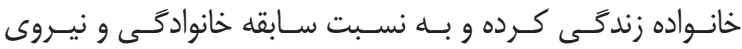

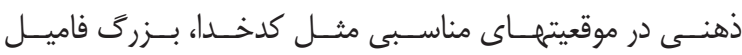

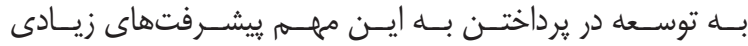

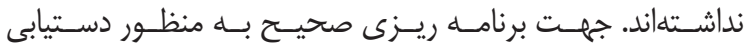

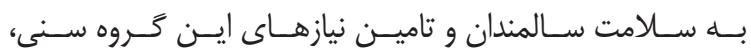

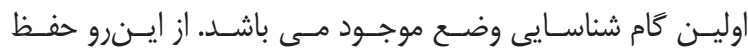

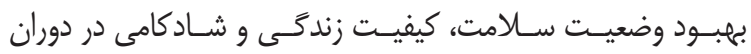

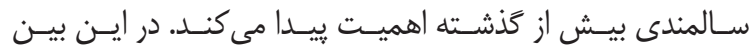

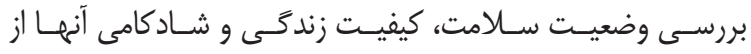

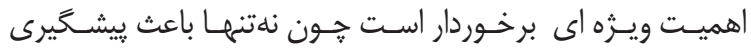

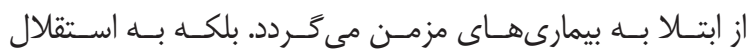

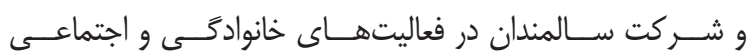

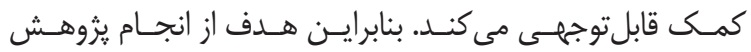
حاضر بررسى مقايسـهاى سـالمندان سـاكن در سـراى سـالمندان،

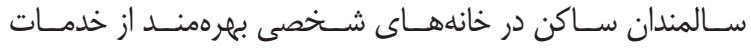

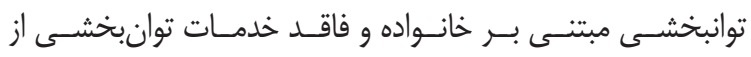
لحساظ سـامت عمومسى ، كيفيـت زندكَى و شـادكامى بــود.

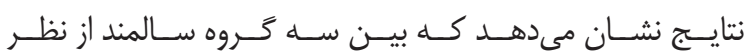

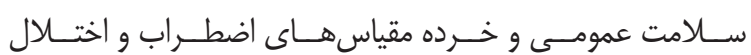

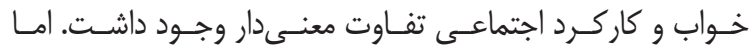

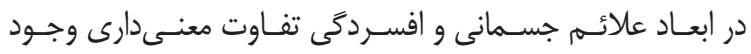

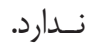

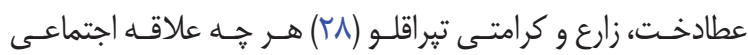

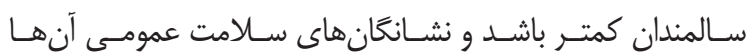

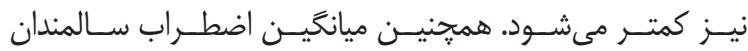

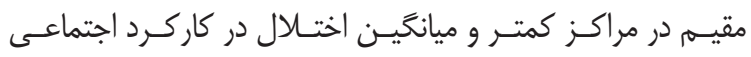

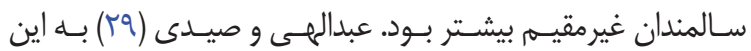

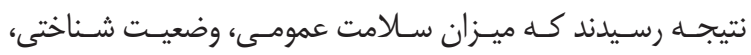

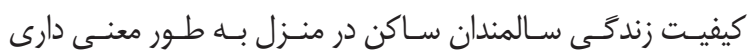

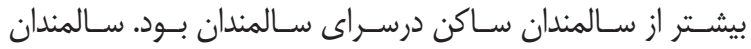

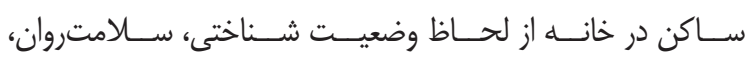

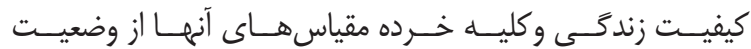

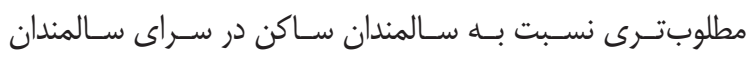

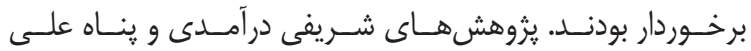

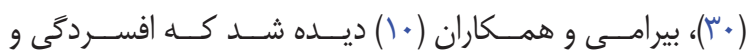

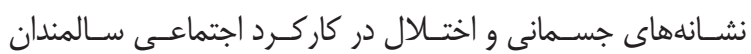

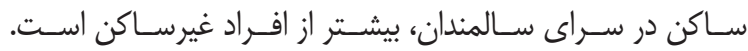

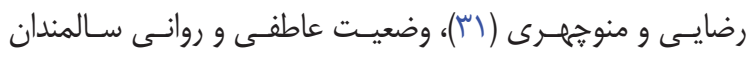

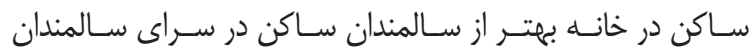

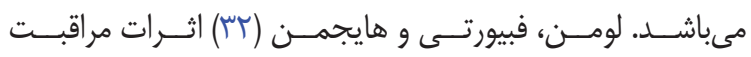

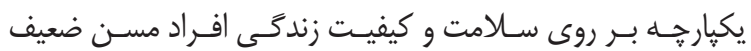

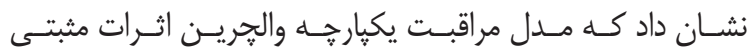

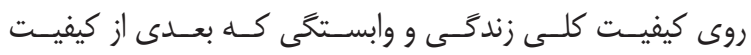




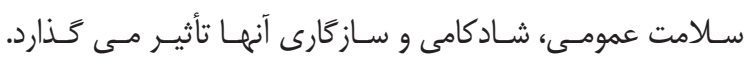

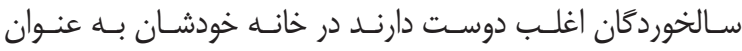

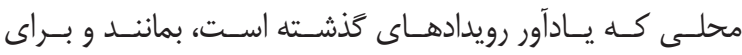

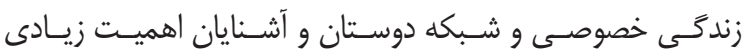

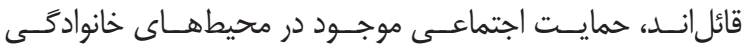

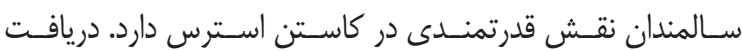

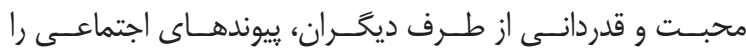

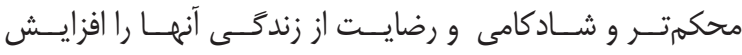
مى دهــــ.

\section{نتيجه كيرى}

توانايسى سـالمندان در انجــام فعاليـت هــاى روزانــه زندگى (بــا و

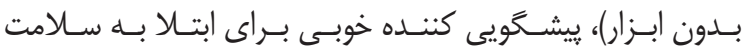

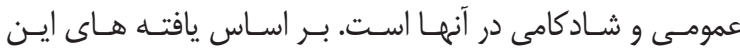

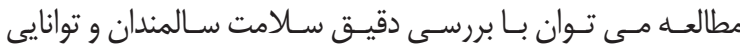

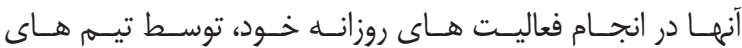

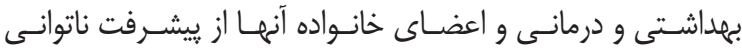

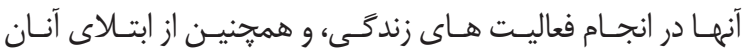

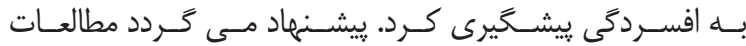

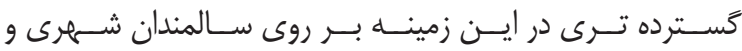

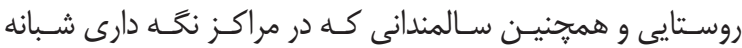
روزى سـالمندان يـا سـالمندان بسـترى در بيمارسـتان نيز در سـاير نقــاط كشـور انجـام گَردد.

\section{تشكر و قدردانى}

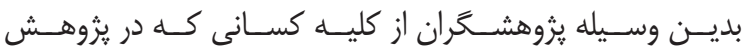

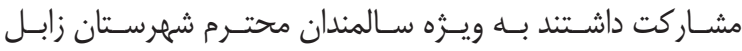
سباسـخزارى مينمايسـد.

\section{Refrences}

1. Hojjati H, Sharifnia SH, Hassanalipour S, Akhonzadeh G, Asayesh H. The effect of reminiscence on the amount of group self-esteem and life satisfaction of the elderly. Bimonthly Urmia Nursing Midwifery. 2012; 9 (5):350-6. (Persian).

2. Mirzaei M, Shams-ghahfarkhi M. The elderly population in the censuses of 1976-2006. Salmand: Iranian Journal of Ageing. 2007; 2 (5): 326-31. (Persian)

3. Sharifzadeh G, Moudi M, Akhbari S. [Investigating health status of older people supported by Imam Khomeini. Salmand: Iranian Journal of Ageing. 2013; 3(7):52-60. (Persian).

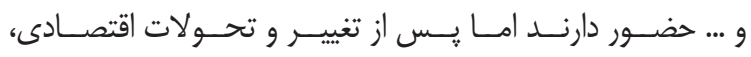
فرهنَ

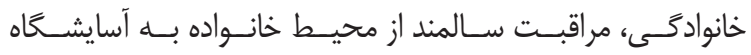

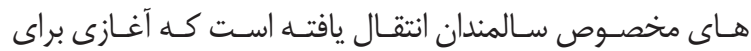

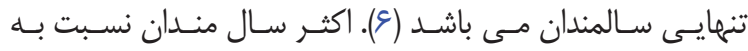

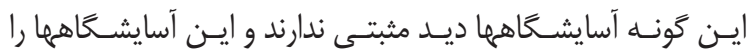

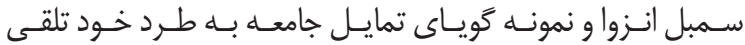

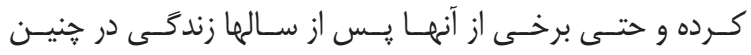

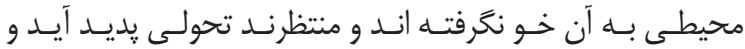

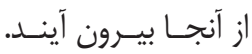

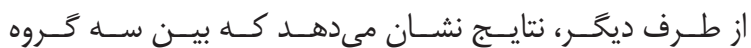

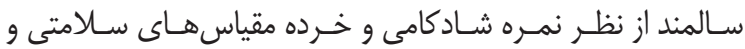

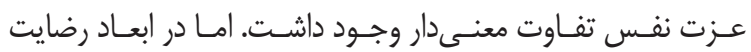

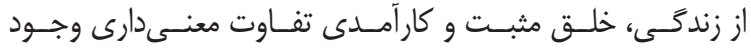

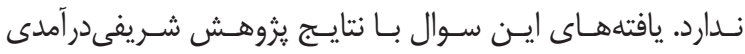

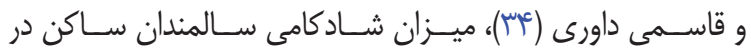

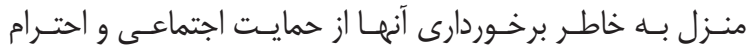

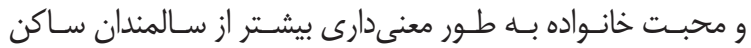
در سـراى سـالمندان اسـت. مكبريـان، كاشـانى، كاشـانى و نامـــار

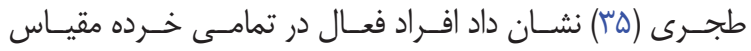

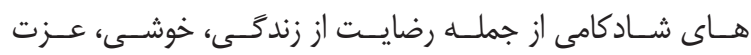

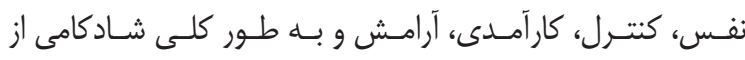

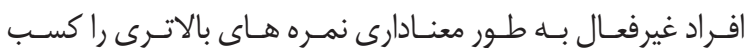

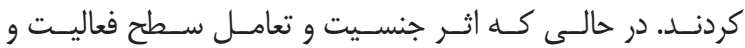

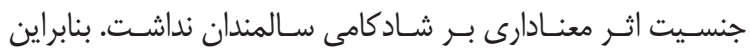

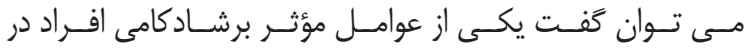

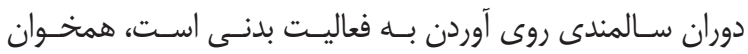

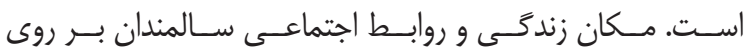

4. Rostami M, Baraz Pordanjani S, Farzianpour F, Rasekh A. Effect of Orem Self Care Model on ederies' quality of life in health care centers of Masjed Solaiman in 2007-2008. Journal of Arak University of Medical Sciences. 2009; 12 (2): 51-9 (Persian).

5. Azadbakht M, Garmaroodi G, Taheri Tanjani P, Sahaf R, Shojaeizade D, Gheisvandi E. Health promoting self-care behaviors and its related factors in elderly: application of health belief model. J Educ Community Health. 2014; 1(2): $20-9$.

6. F. A review of the Iran's elderly status according to the census records. Galen Medical Journal. 2016; 5 (1):1-6. 
7. Hemmatialam Darlou G, Dehshiri G, Shojaee S, Hakimirad A. Comparison of loneliness and public health in older people residing in homes and nursing homes in the North of Tehran. Salmand Iranian Journal of Ageing. 2009; 3 (8): $557-63$.

8. Sadock B, Sadock V. Synopsis of psychiatry. 20th ed. Philadelphia: Lippincott Williams and Wilkins; 2007.

9. Petersen PE. Global policy for improvement of oral health in the 21st century-implications to oral health research of World Health Assembly 2007, World Health Organization. Community dentistry and oral epidemiology. 2009 Feb; 37 (1): $1-8$

10. Luchesi BM, de Oliveira NA, de Morais D, de Paula Pessoa RM, Pavarini SC, Chagas MH. Factors associated with happiness in the elderly persons living in the community. Archives of gerontology and geriatrics. 2018 1; 74: 83-7.

11. El-Gilany AH, Alam RR. Effects of nursing program as a life review on life satisfaction and happiness among elderly people. QJM: An International Journal of Medicine. 2018;111(suppl_1):hcy200-064.

12. Schwarz N, Strack F. Evaluating one's life: A judgment model of subjective well-being. Subjective Well- Being: An Interdisciplinary Perspective. Oxford: Pergamon Press; 1991.

13. Diener E, Oishi S, Lucas RE. Personality, culture, and subjective well-being: Emotional and cognitive evaluations of life. Annual review of psychology. 2003; 54 (1): 403-25.

14. Sheykhi A, Navidian A, Keykha R, Rezaee N. Effect of reminiscence on the happiness the retired elderly members of the Islamic Republic of Iran Army. Iran Journal of Nursing. 2019;32 (119):1-1.

15. Wang X. Subjective well-being associated with size of social network and social support of elderly. Journal of health psychology. 2016; 21(6):1037-42.

16. Gang M, Ko H, Lee J. Aging Anxiety and Subjective Well-being of Persons with Mental Disorder. The Journal of the Korea Contents Association. 2019; 19 (1): 329-38.

17. Adler MG, Fagley NS. Appreciation: Individual differences in finding value and meaning as a unique predictor of subjective well-being. Journal of personality. 2005; 73 (1): 79-114.
18. Vener J. Developmental psychology. Tehran: Savalan Publication; 2009. (Persian).

19. Asakawa K, Feeny D, Senthilselvan A, Johnson JA, Rolfson D. Do the determinants of health differ between people living in the community and in institutions?. Social science \& medicine. 2009; 69 (3): 345-53.

20. Winningham RG, Pike NL. A cognitive intervention to enhance institutionalized older adults' social support networks and decrease loneliness. Aging \& mental health. 2007;11(6):716-21.

21. Kang YS, Kim ES, Gu MO, Eun Y. A study on the health status and the needs of health-related services of female elderly in an urban-rural combined city. Journal of Korean Public Health Nursing. 2003; 17 (1):47-57.

22. Hatamizadeh N, Aminzadeh A, Mirarkhani SM, Kazemnejad A. Study of the success rate of "Family Education" service of community-based rehabilitation scheme for families with physicalmotor disability. Journal of Rehabilitation.2011; 5 (3): 37-44. (Persian).

23. Sharifzadeh M, Khandan H, Abdollahzadeh Gh. Evaluating the Effectiveness of a CommunityBased Rehabilitation Plan on empowerment of rural women in Birjand. Local Development (Rural-Urban). 2016; doi: 10.22059/ jrd.2017.67454. (Persian).

24. Iravani $M$, Hatamizadeh $\mathrm{N}$, Fotohi A, Hosseinzadeh S. Comparison of the Effects of Two New Methods of Family Education in the Community Based Rehabilitation Program on Knowledge, Skill and Attitudes of Local Rehabilitation Staff. Journal of Rehabilitation.2011; 12 (3): 44-51. (Persian).

25. Goldberg DP, Hillier VF. A scaled version of the General Health Questionnaire. Psychological medicine. 1979 Feb;9 (1):139-45.

26. Sotoudeh Nervood, SO, Pour Agha Roodbordeh F, Kafi SM, Pour Sanai, Gh. Sadat. The Effectiveness of Group-Based Memorization on Mental Health of Old Men. Journal of Guilan University of Medical Sciences; 2013; 22 (85): 61-67. (Persian).

27. Argyle M, Lu L. The happiness of extraverts. Personality and individual differences. 1990 Jan 1;11(10):1011-7.

28. Ali Pour A. Noor Bala A. Preliminary Study of Reliability and Validity of Oxford Happiness 
Questionnaire in Tehran University Students. Iranian Journal of Psychiatry and Clinical Psychology.1999; 5 (1 \& 2): 55-66. (Persian).

29. Atadkht A, Zare R, Keramati Tepraqlu N.The Relationship between Social Interest Rate and General Health of Non-Resident Elderly and Resident in Nursing Centers in Ardabil. Health education and health promotion.2015; 3 (2): 141149. (Persian).

30. Abdollahi, M, Seidi Z. Comparison of cognitive status, mental health and quality of life in the elderly living in residential homes in Tehran. Journal of Health Breeze.2016; 3 (2): 23-37. (Persian).

31. Sharifi Daramadi, P, Pana'ah Ali A. Comparison of the Happiness of the Elderly Residents at the Nursing Home and Home. Iranian Journal of Ageing.2011; 6 (3): 49-55. (Persian).

32. Rezaei S, Manouchehri, M. Comparison and comparison of mental disorders of elderly people living in homes and elderly living in nursing homes in Tehran. Iranian Journal of Ageing;2008; 3 (1): 16-25. (Persian).

33. Looman W, Fabbricotti I, Huijsman R. Effects of an integrated care intervention on frail elderly's health and quality of life: a quasi-experimental study. International Journal of Integrated Care. 2015 May 27;15 (5).

34. Sixsmith J, Sixsmith A, Fänge AM, Naumann D, Kucsera CS, Tomsone S, Haak M, DahlinIvanoff S, Woolrych R. Healthy ageing and home: The perspectives of very old people in five European countries. Social Science \& Medicine. 2014 Apr 1; 106: 1-9.

35. Sharifi Payam P, Ghasemi Davari, L. Comparison of emotional insight, self-esteem and depression in victimized and towarded girls aged 15 to 18 years in Tehran in 2010-2011. Psychology of Exceptional Person. 2012; 7 (18): 115-132. (Persian).

36. Makbarian M, Kashani, V, Kashani, K, Namdar Tajri, S. Comparison of the happiness of active and passive elderly women and men in Tehran. Motion-growth and learning-movement movement. Movement.2014; 6 (2): 183-194. (Persian). 